\title{
Produtividade de tomate tipo cereja cultivado em ambiente protegido e em diferentes substratos
}

\author{
Mônica T A de Gusmão ${ }^{1}$; Sérgio A L de Gusmão ${ }^{1}$; Jairo A C de Araújo \\ ${ }^{1}$ UFRA-ICA, Av. Presidente Tancredo Neves, 2501, 66077-530, Belém-PA; ${ }^{2}$ UNESP-FCAV-Dep ${ }^{\text {to }}$. Engenharia Rural, Via de Acesso Prof. \\ Paulo Donato Castellane, s/n ${ }^{\circ}$ 14884-900 Jaboticabal-SP; E-mail: monica.gusmao@ufra.edu.br
}

\section{RESUMO}

O experimento foi realizado em Jaboticabal-SP, sob ambiente protegido, objetivando avaliar quatro substratos (Rendimax-Estu$\mathrm{fa}^{\circledR}$, areia, solo coberto com filme de polietileno preto e solo descoberto) e quatro híbridos de tomateiro tipo cereja ('Mascot', 'Gisela', 'Cheri' e 'Sweet Million'), sendo os substratos comercial e areia acondicionados em sacos plásticos. O delineamento experimental foi em blocos casualizados, em esquema fatorial $4 \times 4$, com quatro repetições. Utilizou-se irrigação por gotejamento, sendo a dotação hídrica realizada em função dos dados obtidos em um tanque Classe A. A solução nutritiva utilizada foi a recomendada por Castellane \& Araújo (1995) para a cultura do tomateiro. Os frutos foram colhidos semanalmente, durante o período de 24/11/2000 a 24/01/2001, sendo avaliados o número e produtividade diária de frutos. Os cultivos em solo proporcionaram maior produção diária que no substrato comercial e em areia, para os híbridos Gisele e 'Mascot'. O híbrido 'Gisela' mostrou-se mais produtivo nos cultivos em solo, enquanto o híbrido 'Cheri', embora tenha proporcionado menores produções em peso, produziu maior número de frutos por planta. A produtividade dos tratamentos mais produtivos foi satisfatória, estando de acordo com os padrões de produção para a cultura no Brasil.

\begin{abstract}
Productivity of cherry tomato cultivated in a protected environment and in different substrates

The experiment was carry out in Jaboticabal-SP, under a protected environment, aiming to evaluate four substrates of root development (substrates Rendimax ${ }^{\circledast}$, sand, soil with mulch of black polyethylene film and soil without mulch) and four hybrids of cherry tomato ('Mascot', 'Gisela', 'Cheri' and 'Sweet Million'). The experimental design was a randomized complete blocks, in a factorial array $(4 \mathrm{x}$ 4 ), with four replications. The irrigation/fertigation was done with a trickle system, being the hydric dotation established based upon the measurements of the class A pan. The nutritious solution was recommended by Castellane \& Araújo (1995) for tomato cropping. The fruits were harvested from 24/11 to 24/01, the number and daily productivity of fruits being appraised. The cultivations in soil provided higher production than in the commercial and sand substrates. The hybrid 'Gisela' was shown to be more productive in the cultivations in soil, while the hybrid 'Cheri', although it provided smaller productions in weight, produced larger number of fruits for plant. The productivity, of the most productive treatments was satisfactory, being in agreement with the production for the culture in Brazil.
\end{abstract}

Keywords: Lycopersicon esculentum Mill., protected cultivation, cherry tomato, hybrids, nutrition.

Palavras-chave: Lycopersicon esculentum Mill., cultivo protegido, tomate cereja, híbridos, nutrição.

\section{(Recebido para publicação em 24 de outubro de 2005; aceito em 18 de dezembro de 2006)}

$\mathrm{O}$ cultivo de tomateiro em ambiente protegido expandiu-se muito na região Sudeste, principalmente no Estado de São Paulo, atualmente o terceiro centro produtor do Brasil, superado apenas por Goiás e Minas Gerais, nesta ordem (Fontes et al., 1997). A utilização do tomate tipo cereja como adorno, aperitivo e na confecção de pratos diversos é uma opção a mais de consumo dessa hortaliça (Gusmão et al., 2000a). De acordo com Lopes \& Stripari (1998), o tomateiro é uma planta muito sensível às condições climáticas e estas, quando desfavoráveis e aliadas a outros fatores, contribuem para que seu cultivo, em condições protegidas, aumente rapidamente nos últimos anos.

O uso de filme plástico como cobertura ("mulch"), conserva a umidade e a temperatura do solo, diminuindo a am- plitude térmica e a umidade relativa, favorecendo ainda o metabolismo da planta e a precocidade do ciclo vegetativo (Lopes, 1997; Martins et al., 1999). Por outro lado, de acordo com Moraes \& Furlani (1999), o uso intensivo do solo em condições de ambiente protegido, promove sua contaminação por bactérias, fungos e nematóides fitopatogênicos, além da salinização do mesmo. Esses problemas, em algumas regiões, têm limitado a produção nesse sistema e, os produtores nem sempre dominam técnicas para solucioná-los. Entretanto, uma alternativa para contornar esses problemas em cultivo protegido é a utilização de substratos removíveis associados com a fertirrigação por gotejamento.

Vários requisitos são importantes para o uso de um substrato hortícola associado à fertirrigação, tais como: alta capacidade de retenção de água, aeração satisfatória, boa capacidade de tamponamento, ausência de pragas e agentes fitopatogênicos, ausência de inibidores de crescimento e pouca atividade biológica (Martinez \& Barbosa, 1999). É ainda fundamental que as propriedades físicas, químicas e biológicas permaneçam as mesmas por longo período de tempo, para que os processos do sistema de cultivo possam ser padronizados (Abad Berjon \& Noguera Murray, 1998; Röber, 2000).

De acordo com Norrie et al. (1994) e Marouelli et al. (2002b), o sucesso do cultivo em substrato depende da otimização de diversas variáveis, dentre as quais as práticas de irrigação e nutrição. $\mathrm{O}$ volume explorado pelo sistema radicular da cultura é reduzido, 
assim como a retenção de água pelo substrato. Assim, as irrigações devem ser realizadas em regime de alta freqüência (até 20 por dia) e baixo volume, o que torna o manejo de água um fator limitante para a obtenção de altos rendimentos e a racionalização no uso de água e nutrientes.

O uso de substratos está relacionado, em geral, com o cultivo em recipientes, seja em sacos plásticos, latas, vasos ou bandejas. Em comparação com o cultivo em solo, onde as plantas dispõem de um volume ilimitado para o crescimento de suas raízes, no cultivo em recipientes esse volume é bastante reduzido, o que diminui a drenagem e a superfície de contato com a atmosfera, essencial para as trocas gasosas (Kämpf, 2000).

O sistema de cultivo em substratos, especialmente sob irrigação por gotejamento, limita, portanto, o crescimento das raízes a um volume menor, cujas condições de contorno são determinadas pelos limites físicos do contentor, disponibilidade de água e nutrientes, nível de salinidade e aeração no substrato (Marfá \& Guri, 1999). Estudando a distribuição do sistema radicular do tomateiro, em substratos acondicionados em sacos de cultivo, Marouelli et al. (2002a) observaram que a maior concentração de raízes se deu nas proximidades do gotejador. Observaram ainda, que o crescimento das raízes foi determinado principalmente pela salinidade ao longo do contentor de substrato, que variou de 2,0 a 8,3 dS $\mathrm{m}^{-1}$, dependendo do tipo de substrato e da posição do gotejador no contentor: quanto mais afastado do gotejador maior a salinidade.

Gualberto et al. (2000), observaram que híbridos de tomateiro apresentam diferentes padrões de estabilidade e adaptabilidade. Portanto, é esperado que tenham comportamento diferenciado, já que são provenientes de diferentes produtores de sementes, utilizando genótipos bem distintos na formação dos híbridos. Pádua et al. (2002 a,b), comparando dois híbridos de tomateiro tipo cereja ('Cheri' e 'Sindy') em cultivo sob ambiente protegido não obtiveram diferenças em produtividade por planta, em função da temperatura.
Existem citações sobre a possibilidade de crescimento das plantas por até dez metros de comprimento (Lopes \& Stripari, 1998). Entretanto, há poucas pesquisas com esse tipo de tomateiro no Brasil, em termos de cultivares, substratos e sistemas de cultivo.

O presente trabalho teve por objetivo avaliar o cultivo de híbridos de tomateiros tipo cereja em substratos de cultivo e em solo coberto com filme de polietileno preto e em descoberto, nas condições de primavera-verão, em Jaboticabal-SP.

\section{MATERIAL E MÉTODOS}

$\mathrm{O}$ experimento foi conduzido em Jaboticabal-SP, latitude de $21^{\circ} 15^{\prime} 22^{\prime \prime}$, longitude de $48^{\circ} 18^{\prime} 58^{\prime \prime} \mathrm{W}$ e altitude de $595 \mathrm{~m}$, com médias anuais de precipitação de $1552 \mathrm{~mm}$, temperatura de $22^{\circ} \mathrm{C}$ e umidade relativa do ar de $70 \%$ (Volpe et al., 1989).

O ambiente protegido, do tipo capela, com pé direito de quatro metros, 30 $\mathrm{m}$ de comprimento e $10 \mathrm{~m}$ de largura, foi coberto com filme de polietileno transparente aditivado contra raios ultravioleta, com $150 \mathrm{~mm}$ de espessura e laterais protegidas com telas de polipropileno preto (sombrite ${ }^{\circledR}$ ) com $30 \%$ de sombreamento. Os tratamentos consistiram de quatro substratos (Rendimax-Estufa ${ }^{\circledR}$, areia, solo coberto com filme de polietileno preto e a testemunha constituída pelo solo descoberto) e de quatro híbridos de tomateiro tipo cereja ('Mascot', 'Gisela', 'Cheri' e 'Sweet Million'). O solo utilizado é aquele da própria área do experimento e foi classificado como LATOSSOLO VERMELHO ESCURO Embrapa (1999).

O experimento foi conduzido em delineamento blocos casualizados, esquema fatorial $4 \mathrm{x}$, com quatro repetições. A parcela experimental constituiu de fileiras duplas, espaçadas de 1,00 x $0,60 \times 0,30 \mathrm{~m}$, com densidade aproximada de quatro plantas $\mathrm{m}^{-2}$, totalizando 12 plantas, tendo como área útil, as oito plantas centrais de cada parcela. No cultivo em substrato comercial e em areia, foram utilizadas três plantas por saco, mantendo-se a densidade aproximada de quatro plantas $\mathrm{m}^{-2}$.
Os híbridos foram escolhidos a partir de consultas feitas às empresas produtoras de sementes ou seus representantes no Brasil, sendo todos indicados para plantio em ambiente protegido ou a campo, possuindo boa produtividade e coloração vermelha de fruto, com resistência ao vírus do mosaico-do-tabaco (TMV), Fusarium raças 1 e 2 e Verticillium, a exceção do híbrido 'Sweet Million' que é resistente ao vírus do mosaico do tomate (ToMV), Fusarium raça 1 e Stemphylium.

A semeadura foi realizada no dia 06/ 09/2000, em bandejas de poliestireno expandido, com 128 células, distribuindo-se uma semente por célula e utilizando-se o substrato comercial Plantimax ${ }^{\circledR}$. As mudas foram produzidas em sistema de nebulização e sombreamento com redução em $30 \%$ da luminosidade. Neste período, foi efetuada uma aplicação com Thiametoxam, para controle de mosca branca (Bemisia argentifolli).

O transplantio foi realizado em 02/ $10 / 2000$, quando as plantas apresentavam quatro a cinco folhas definitivas.

Para o preparo do solo realizou-se aração e gradagem. Após estas operações, incorporou-se $150 \mathrm{~g} \mathrm{~m}^{-2}$ de calcário dolomítico à profundidade mínima de $20 \mathrm{~cm}$ (60 dias antes do transplantio das mudas) e, levantou-se canteiros com largura de $0,80 \mathrm{~m}$ e altura de $0,20 \mathrm{~m}$. No tratamento de solo com cobertura, foi utilizado o mesmo procedimento, sendo que a seguir os canteiros foram cobertos com o filme de polietileno preto, com espessura de 0,05 mm.

As características químicas do substrato comercial, solo e areia podem ser observados nas Tabelas 1, 2 e 3.

O substrato comercial utilizado já se encontrava acondicionado em sacos de cultivo, com dimensões de $0,40 \mathrm{~m}$ de largura, 0,15 m de altura e 0,90 m de comprimento, produzido pela Empresa Eucatex, com nome comercial de Rendimax-Estufa ${ }^{\circledR}$. Cada saco de cultivo comportou $15 \mathrm{~kg}$ de substrato comercial, constituído de casca de pinus compostada, vermiculita expandida, perlita expandida e turfa. Esses sacos de cultivo apresentavam microperfurações para facilitar a drenagem do excesso de água e aeração do meio. Em vista disso, tornou-se necessário a cobertura do solo, 
sob os sacos de cultivo com filme de polietileno, para evitar possível contaminação por fitopatógenos e desenvolvimento de raízes fora do recipiente. A areia utilizada também foi acondicionada em sacos plásticos de dimensões iguais às do saco com substrato comercial, sendo essa areia lavada de rio com predominância granulométrica entre $0,10 \mathrm{~mm}$ e $0,5 \mathrm{~mm}$.

A irrigação foi feita diariamente, fracionada em duas ou três aplicações diárias, de acordo com o substrato, sendo controlada por 16 tensiômetros de mercúrio, instalados um em cada tratamento, na profundidade de $0,2 \mathrm{~m}$. Acionava-se o sistema de irrigação quando os tensiômetros atingiam 40 a $60 \mathrm{kPa}$ nos substratos com solo coberto com filme de polietileno preto e na testemunha; no substrato comercial, de 40 a $50 \mathrm{kPa}$, e no substrato areia, de 5 a $20 \mathrm{kPa}$, dependendo do estádio de desenvolvimento da cultura e das condições ambientais (Marouelli et al.,1996). O sistema de irrigação utilizado foi o gotejamento, sendo instalado um gotejador flecha por planta ligado a um conector com quatro saídas, com vazão de $2,0 \mathrm{~L} \mathrm{~h}^{-1}$. A dotação hídrica foi realizada em função dos dados obtidos em um tanque Classe $\mathrm{A}$, instalado no interior do ambiente protegido.

A fertirrigação foi realizada duas vezes por semana, utilizando-se sistema aberto, onde a solução nutritiva era bombeada do reservatório para os diversos tratamentos, sem recirculação. A quantidade de nutrientes para $1.000 \mathrm{~L}$ de solução nutritiva, fornecida através de fertirrigação, foi calculada conforme recomendação de Castellane \& Araújo (1995) para a cultura do tomate, sendo de: $184 ; 21 ; 248 ; 153 ; 43 ; 47,5 ; 0,31$; 0,$06 ; 4,5 ; 0,06 ; 0,4$ e $0,4 \mathrm{mg} \mathrm{L}^{-1}$ de N, P, $\mathrm{K}, \mathrm{Ca}, \mathrm{Mg}, \mathrm{S}, \mathrm{B}, \mathrm{Cu}, \mathrm{Fe}, \mathrm{Mo}, \mathrm{Zn}$ e Mn, respectivamente.

Foi feito o monitoramento da temperatura e da umidade relativa do ar durante o desenvolvimento da cultura, utilizando-se um termohigrógrafo instalado no interior do ambiente protegido sob um abrigo de madeira a $1,0 \mathrm{~m}$ de altura do solo. Também foram registrados os dados das temperaturas dos substratos, sendo para isto, instalados termômetros de solo a $0,05 \mathrm{~m}$ de profundidade.

As plantas foram conduzidas verticalmente em haste única, utilizando-se fita plástica para tutoramento, sendo cultivada uma planta por cova, fazendo-se a eliminação de todos os ramos laterais. Não foi feito o raleio dos frutos.

Os frutos foram colhidos semanalmente, durante o período de 24/11/2000 a 24/01/2001, procurando-se colher os frutos que já haviam iniciado a mudança de coloração, de verde para vermelho, sendo avaliados o número total de frutos, a produtividade total de frutos e a produtividade de frutos por dia.

Os resultados foram analisados por meio de análise de variância pelo teste $\mathrm{F}$ e as médias comparadas pelo teste de Tukey, a 5\% de probabilidade.

\section{RESULTADOS E DISCUSSÃO}

O período no qual o trabalho foi desenvolvido apresentou elevação de temperatura e intensas chuvas, que são fatores limitantes à produção de tomate. Conforme pode ser observado na Figura 1 , neste período a temperatura máxima no ambiente protegido atingiu valores médios semanais superiores a $35^{\circ} \mathrm{C}$, permanecendo quase que durante todo o período, superiores a $30^{\circ} \mathrm{C}$. Esses valores de temperatura são considerados limitantes à produção do tomateiro (Martins et al., 1999). Por outro lado, a umidade relativa do ar, manteve-se em valores aceitáveis durante o dia, elevando-se durante a noite. O que reflete os efeitos do sistema de irrigação por gotejamento, mantendo o ambiente mais seco, diminuindo a probabilidade de ocorrência de doenças.

A produtividade de frutos foi influenciada tanto pelos híbridos como pelos substratos, sendo as interações significativas (Tabela 4). O cultivo em sacos com substrato proporcionou menor produtividade do que o cultivo em solo. O híbrido 'Gisela' mos- trou-se mais produtivo do que os demais híbridos no cultivo em solo coberto e descoberto. O híbrido 'Cheri' foi o que apresentou menores produtividades em todos os substratos (Tabela 4), demonstrando que, embora produza inflorescências com elevado número de frutos (Tabela 5), apresenta maior sensibilidade às altas temperaturas ou a fatores nutricionais, levando à redução no tamanho dos frutos formados.

Ao analisar o número de frutos produzidos (Tabela 5), verifica-se que, o fator genético teve grande influência na formação de frutos. 'Cheri' e 'Sweet Million' são híbridos mais característicos dos tomates tipo cereja, uma vez que apresentam inflorescência com elevado número de frutos, enquanto 'Gisela' e 'Mascot' formam frutos maiores (mini) com inflorescências menores e pouco ramificadas. Por isso, embora tenham havido menores produções, em peso, do híbrido 'Cheri', ainda assim, este, obteve maiores valores em número de frutos formados. Esse fato pode ser positivo em regiões quentes, onde é significativa a queda de flores, podendo haver alguma compensação pela quantidade remanescente na planta originando os frutos.

As maiores produtividades obtidas neste trabalho pelo híbrido 'Gisela', em condições de cultivo em solo, são equivalentes às obtidas por Gusmão et al. (2000a; 2000b), em cultivo em condições de campo, com solo coberto com filme de polietileno preto, enquanto que os tratamentos com menores produtividades tiveram valores semelhantes àqueles obtidos por Pádua et al. (2002a, 2002b) em cultivos em ambiente protegido. Esses resultados evidenciam comportamento diferencial de cultivares e de sistemas de cultivo do tomateiro tipo cereja.

A expectativa de aumento em produtividade com o uso de substratos em recipientes não foi confirmada. Esse tipo de resposta também foi obtido por outros autores quando o tomateiro foi cultivado em recipientes (Andriolo et al. 1997; Andriolo et al. 1999; Fernandes 
Tabela 1. Análises químicas do substrato comercial Rendimax-Estufa ${ }^{\circledR}$, do solo e da areia. Jaboticabal-SP, UNESP-FCAV, $2000-2001$.

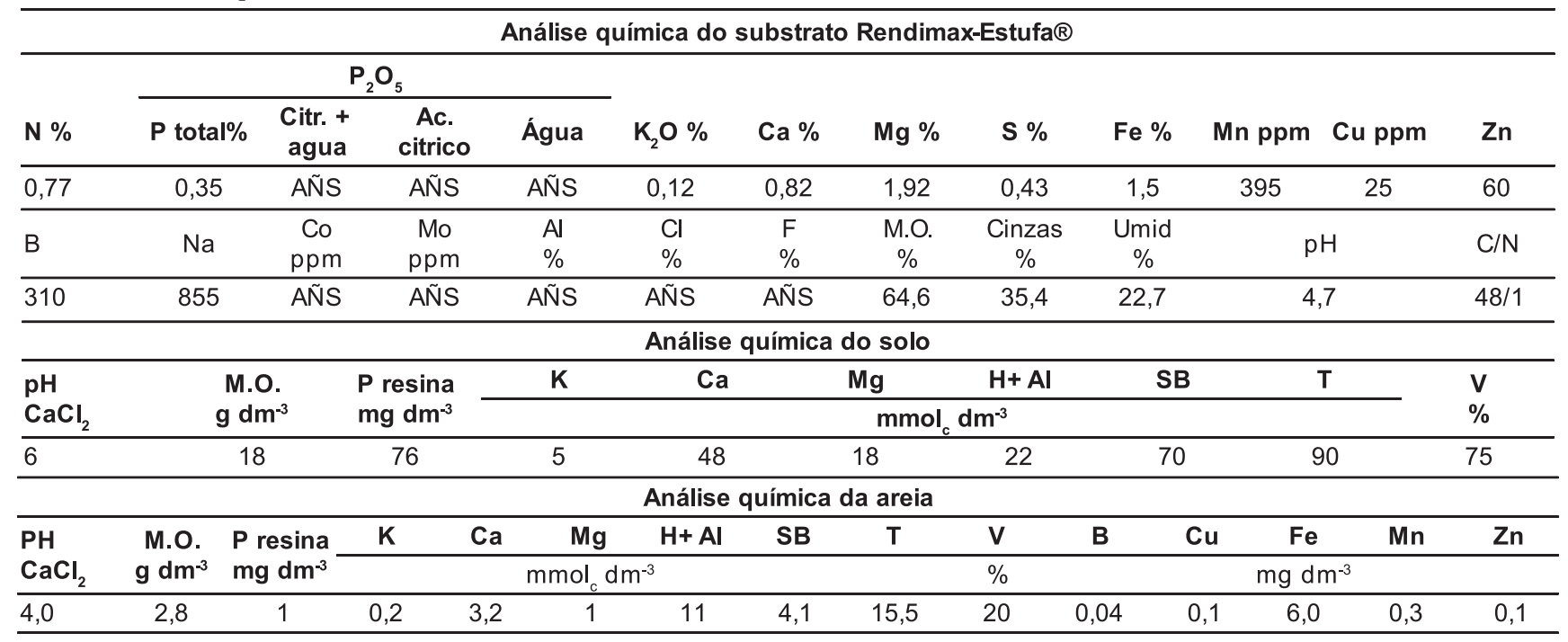

*AÑS: Análise não significativa

Tabela 2. Produtividade de frutos de híbridos de tomateiro tipo cereja, em $\mathrm{kg} \mathrm{m}^{-2}$, cultivados em ambiente protegido e em diferentes substratos. Jaboticabal-SP, UNESP-FCAV, 2000-2001.

\begin{tabular}{llllll}
\hline Hibridos & \multicolumn{5}{c}{ Substratos } \\
\cline { 2 - 6 } & $\begin{array}{c}\text { Rendimax- } \\
\text { estufa }{ }^{8}\end{array}$ & Areia & $\begin{array}{c}\text { Solo } \\
\text { coberto }\end{array}$ & $\begin{array}{c}\text { Solo } \\
\text { descoberto }\end{array}$ & Médias \\
\hline 'Gisela' & $6,01 \mathrm{Bab}$ & $6,25 \mathrm{Ba}$ & $8,96 \mathrm{Aa}$ & $8,81 \mathrm{~A}$ a & 7,51 \\
'Mascot' & $5,16 \mathrm{Bab}$ & $5,16 \mathrm{Ba}$ & $6,66 \mathrm{~A} \mathrm{~b}$ & $7,64 \mathrm{~A} \quad \mathrm{~b}$ & 6,14 \\
'Sweet Million' & $6,24 \mathrm{Ba}$ & $6,23 \mathrm{Ba}$ & $6,02 \mathrm{Bb}$ & $7,67 \mathrm{~A}$ ab & 6,54 \\
'Cheri' & $5,06 \mathrm{~B} \mathrm{~b}$ & $5,88 \mathrm{ABa}$ & $6,57 \mathrm{~A} \mathrm{~b}$ & $6,10 \mathrm{AB} \quad \mathrm{c}$ & 5,90 \\
\hline MÉDIAS & 5,62 & 5,87 & 7,05 & 7,55 & \\
\hline C.V. (\%) & 9,31 & & & & \\
\hline
\end{tabular}

*Médias seguidas de mesma letra maiúscula na horizontal ou minúscula na vertical, não diferem entre si, pelo teste de Tukey $(\mathrm{P}>0,05)$.

Tabela 3. Número de frutos por planta produzidos por híbridos de tomateiro tipo cereja, cultivados em ambiente protegido e em diferentes substratos. Jaboticabal-SP, UNESP-FCAV, 2000-2001.

\begin{tabular}{|c|c|c|c|}
\hline Híbridos & Médias & Substratos & Médias \\
\hline 'Gisela' & 214,98 & Rendimax-Estufa® & 241,36 \\
\hline 'Mascot' & 198,35 & Areia & 234,91 \\
\hline 'Sweet Million' & $283,41 \quad b$ & Solo coberto & $275,10 \quad b$ \\
\hline 'Cheri' & 360,61 a & Solo descoberto & 305,98 a \\
\hline C.V. $(\%)$ & 11,69 & & \\
\hline
\end{tabular}

*Médias seguidas de mesma letra, na vertical, não diferem entre si, pelo teste de Tukey $(\mathrm{P}>0,05)$.

et al., 2002; Pádua et al. 2002a). Provavelmente a baixa qualidade dos substratos utilizados no Brasil seja uma das razões, por não reunirem um conjunto de características físicas, químicas e biológicas adequadas. Além disso, vários outros fatores influenciaram o comportamento das plantas, tais como com substratos compostos por areia, bagaço de cana e casca de amendoim moída. Marouelli et al. (2002b), fracionaram a irrigação, com ou sem fertilizantes, seis a 18 vezes ao dia, indicando ser essa prática, ponto chave para o sucesso do cultivo em substrato. No presente trabalho, a frequiência de reposição de água variou de duas a três vezes ao dia, o que pode ter influenciado na produção em sistema de sacos de cultivo.

Outro aspecto que merece atenção é a forma de determinar a reposição de água, via tensiômetros e tanque classe A. Fernandes et al. (2002), ressaltam as dificuldades em se determinar a quantidade de água a aplicar em diferentes substratos, quando se usa tensiômetros e tanque classe A. Neste trabalho, podese adicionar os efeitos dos sacos de cultivo e da cobertura do solo com filme de polietileno, que funcionam como uma barreira à evaporação. Portanto, o uso de tanque classe A em trabalhos dessa natureza não é recomendável. Andriolo et al. (1997), citam que, no manejo da água devem ser evitadas variações bruscas do potencial matricial do substrato, especialmente nos períodos de forte demanda evaporativa pela atmosfera. As condições de temperatura e de umidade relativa do ar, no período de realização do experimento, foram favoráveis a esses efeitos. 
Em condições de cultivo em solo, a distribuição de água ao longo do perfil é mais abrangente e reduz a possibilidade de altas concentrações salinas em primeiro cultivo, permitindo um maior desenvolvimento de raízes comparativamente ao sistema de recipientes. Espera-se também, que as concentrações de $\mathrm{CO}_{2}$ e $\mathrm{O}_{2}$ no ambiente radicular sejam favorecidas, enquanto em condições de sacos de cultivos, deverão haver adaptações que reduzam esses problemas, o que pode ser obtido por maior fracionamento da irrigação. Há ainda o efeito positivo de nutrientes no solo, os quais também facilitam o desenvolvimento das plantas.

Uma das formas de avaliar a produtividade das culturas é considerando o seu ciclo, sobretudo sob condições de ambiente protegido, em razão do elevado custo da área. Fontes (1997), ressalta a importância de analisar o comportamento produtivo do tomateiro, por meio da produção por hectare ao dia. Em tomateiros tipo cereja, em que são citadas extensões de hastes de até dez metros e em que o tamanho dos frutos assume menor importância comercial que os tomates tipo salada, a avaliação da produção em relação não só ao espaço, mas considerando também o tempo, permite melhor visualização do cultivo. Na Tabela 6 pode-se observar que a produtividade diária manteve as mesmas tendências comportamentais da produtividade total. Entretanto, os híbridos 'Sweet Million' e ‘Cheri', não diferiram significativamente quando cultivados nos diversos substratos avaliados, enquanto que 'Gisela' e 'Mascot' apresentaram maior produção em $\mathrm{g} \mathrm{m}^{-1}$ dia $^{-1}$ cultivados em solos coberto e descoberto. É possível se observar que os valores de produtividade diária, dos tratamentos mais produtivos são satisfatórios, estando de acordo com os padrões de produção no Brasil (Agrianual, 2003).

Quanto ao sistema de cultivo, os substratos que possibilitaram maior produção em peso, também favoreceram a formação de frutos por planta em que o solo descoberto foi superior aos demais (Tabela 5). Comparando-se estes resul-

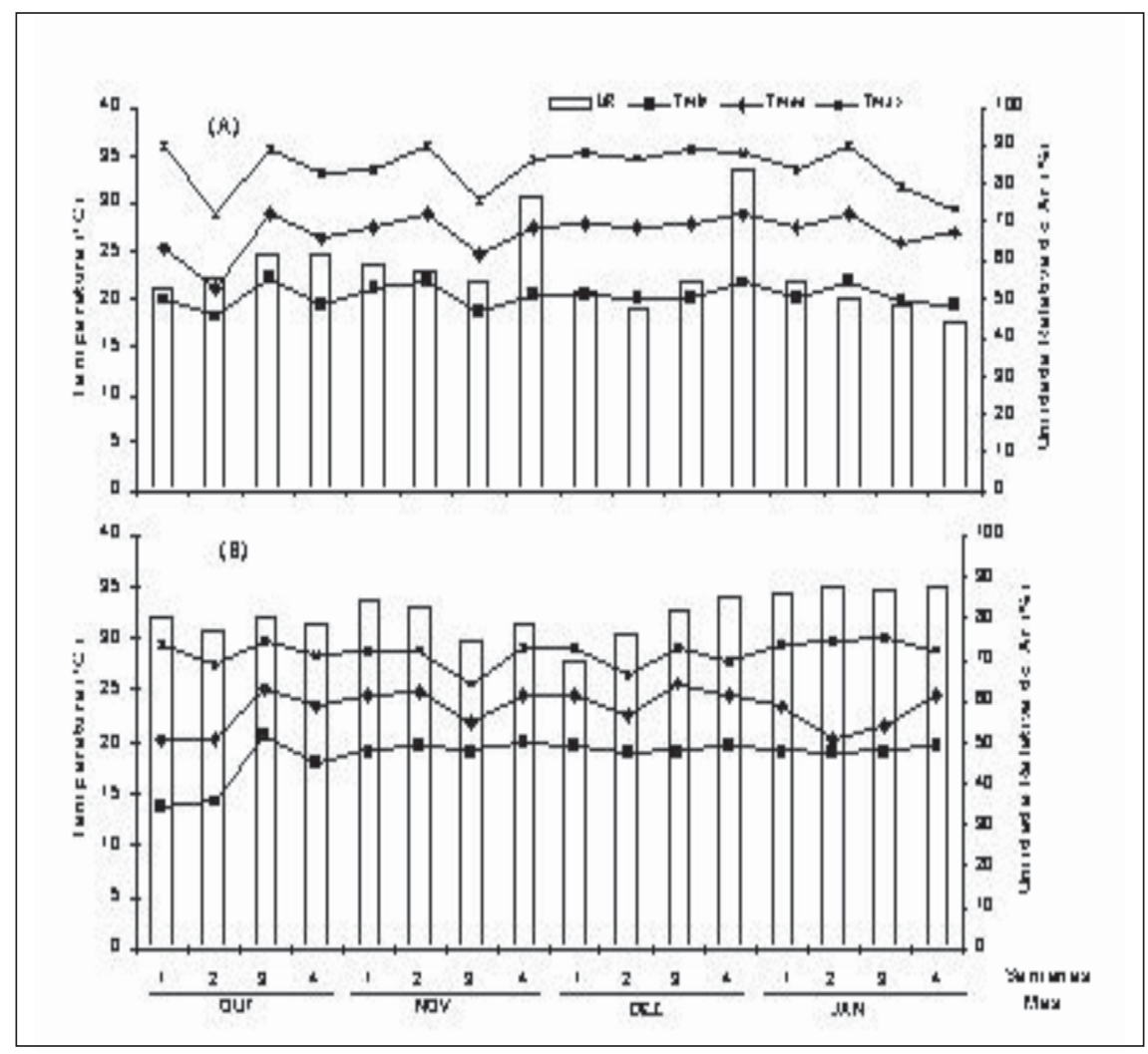

Figura 1. Variações das médias diurnas (A) e noturnas (B) de temperaturas semanais máximas, médias e mínimas e da umidade relativa do ar, medidas no interior do ambiente protegido. Jaboticabal-SP, UNESP-FCAV, 2000-2001.

Tabela 4. Produtividade de frutos de híbridos de tomateiro tipo cereja, em $\mathrm{g} \mathrm{m}^{-2} \mathrm{dia}^{-1}$, cultivados em ambiente protegido e em diferentes substratos. Jaboticabal-SP, UNESP-FCAV, 2000-2001.

\begin{tabular}{llllllll}
\hline Híbridos & \multicolumn{7}{c}{ Substratos } \\
\cline { 2 - 8 } & $\begin{array}{c}\text { Rendimax- } \\
\text { estufa }{ }^{8}\end{array}$ & Areia & $\begin{array}{c}\text { Solo } \\
\text { coberto }\end{array}$ & $\begin{array}{c}\text { Solo } \\
\text { descoberto }\end{array}$ & Médias \\
\hline Gisele & $51,3 \mathrm{Ba}$ & $49,0 \mathrm{Ba}$ & $80,0 \mathrm{~A} \mathrm{a}$ & $79,4 \mathrm{~A}$ a & 64,9 \\
'Mascot' & $42,0 \mathrm{Ba}$ & $40,8 \mathrm{Ba}$ & $57,2 \mathrm{~A}$ & $\mathrm{~b}$ & $62,7 \mathrm{~A}$ & $\mathrm{~b}$ & 50,7 \\
'Sweet Million' & $48,6 \mathrm{~A} \mathrm{a}$ & $49,1 \mathrm{~A}$ a & $49,4 \mathrm{~A}$ & $\mathrm{~b}$ & $56,7 \mathrm{~A}$ & $\mathrm{~b}$ & 50,9 \\
'Cheri' & $41,6 \mathrm{~A}$ a & $44,1 \mathrm{~A}$ a & $54,0 \mathrm{~A}$ & $\mathrm{~b}$ & $51,7 \mathrm{~A}$ & $\mathrm{~b}$ & 47,8 \\
\hline MÉDIAS & 45,9 & 45,7 & 60,1 & 62,6 & \\
\hline C.V. $(\%)$ & 14,05 & 7 & & & \\
\hline
\end{tabular}

*Médias seguidas de mesma letra maiúscula na horizontal ou minúscula na vertical, não diferem entre si, pelo teste de Tukey $(\mathrm{P}>0,05)$.

tados com os de outros trabalhos, podese observar que são semelhantes aos de Pádua et al. (2002a), com cultivo de tomate cereja em substrato, e superiores aos de Gusmão et al. (2000a) e Pádua et al. (2002b), que trabalharam respectivamente em campo e em casa de vegetação, avaliando os efeitos da cobertura do solo com filme de polietileno preto.

De acordo com Goto (1995), a capacidade ótima de fixação de frutos em tomateiro requer temperaturas noturnas entre $15^{\circ} \mathrm{C}$ e $20^{\circ} \mathrm{C}$. A queda de flores em tomateiro pode ser provocada por temperaturas excessivamente elevadas durante o dia, principalmente acima de $32^{\circ}$ $\mathrm{C}$ e com mais de três horas. Além de provocar a queda de flores, devido a inviabilidade do pólen e/ou não fertilização dos óvulos, as temperaturas elevadas também prejudicam a fixação dos frutos. 
O fator genético pode ter interferido tanto por razões anatômicas das plantas, uma vez que as inflorescências possuíam número diferente de flores, como também pela maior tolerância às condições adversas de clima. Segundo Grilli et al. (2000), há genótipos mais adaptados a altas temperaturas que outros.

Conclui-se que há necessidade de ajustes de irrigação e da nutrição para sistemas de cultivo e que esses são mais relevantes quando são utilizados sistemas de plantio em sacos de cultivo. A escolha do híbrido para cultivo, além da preferência de mercado, deve levar em consideração as características de adaptação às condições do clima e o sistema de cultivo a se utilizar. Embora o cultivo em solo tenha apresentado melhores resultados de produtividade, deve-se considerar que não haviam fatores restritivos à produção em solo, principais justificativas para se adotar o cultivo em substrato.

\section{REFERÊNCIAS}

ABAD BERJON M; NOGUERA MURRAY P 1998. Substratos para el cultivo sin suelo $y$ fertirrigation. In: LOPES, C.C. (Coord.) Fertirrigation horticolas y ornamentales. Madrid: Mundi-Prensa. p.287-342.

AGRIANUAL 2003: anuário estatístico da agricultura brasileira. São Paulo: FNP Consultoria \& Comércio. p.515-526.

ANDRIOLO JL; DUARTE TS; LUDKE L; SKREBSKY EC. 1997. Crescimento e desenvolvimento do tomateiro cultivado em substrato com fertirrigação. Horticultura Brasileira 15: 28-32.

ANDRIOLO JL; DUARTE TS; LUDKE L; SKREBSKY EC. 1999. Caracterização e avaliação de substratos para o cultivo do tomateiro fora do solo. Horticultura Brasileira 17: 215-219.

CASTELLANE PD; ARAÚJO JAC. 1995. Cultivo sem solo-hidroponia. Jaboticabal: FUNEP. $43 \mathrm{p}$

EMBRAPA. 1999. Sistema brasileiro de classificação de solos. Brasília, Embrapa Produção de Informação. Rio de Janeiro: Embrapa Solos. 412 p.
FERNANDES C; ARAÚJO JAC; CORÁ JE. 2002. Impacto de quatro substratos e parcelamento da fertirrigação na produção de tomate sob cultivo protegido. Horticultura Brasileira 20: 559-563.

FONTES PCR. 1997. Produtividade do tomateiro: $\mathrm{kg} / \mathrm{ha}$ ou $\mathrm{kg} / \mathrm{ha} \mathrm{x}$ dia? Horticultura Brasileira 15: 83-84.

FONTES PCR; DIAS EN; ZANIN SR; FINGER FL. 1997. Produção de cultivares de tomate em estufa coberta com plástico. Revista Ceres 44: 252-260.

GOTO R. 1995. Manejo nutricional no cultivo de hortaliças em estufa. In: ENCONTRO DE HORTALIÇAS, 9, ENCONTRO DE PLASTICULTURA DA REGIÃO SUL, 6. Palestras e trabalhos apresentados... Maringá: Universidade Estadual de Maringá. p.11-18.

GRILLI GVG; BRAZ LT; FIGUEIREDO EB de. 2000. Fixação de frutos de tomateiro submetidos as altas temperaturas. Horticultura Brasileira 18: 725-727.

GUALBERTO R; BRAZ LT; BANZATTO DA. 2000. Produtividade, adaptabilidade e estabilidade fenotípica de cultivares de tomateiro sob diferentes condições ambientais. Jaboticabal: UNESP-FCAV. 93p. (Tese doutorado).

GUSMÃO SAL de; PÁDUA JG; GUSMÃO MTA de; BRAZ LT. 2000a. Efeito da densidade de plantio e forma de tutoramento na produção de tomateiro tipo "cereja" em Jaboticabal-SP Horticultura Brasileira 18: 572-573.

GUSMÃO SAL de; PÁDUA JG; GUSMÃO MTA de; BRAZ LT. 2000b. Efeito da cobertura do solo com filme de polietileno e da densidade de plantio, na produção de tomateiro tipo cereja. Horticultura Brasileira 18: 571-572.

KÄMPF AN. 2000. Seleção de materiais para uso como substrato. In: KÄMPF AN; FERMINO MH (ed). Substrato para plantas-a base da produção vegetal em recipientes. Porto Alegre: Genesis. p. 139-145.

LOPES MC; STRIPARI PC. 1998. A cultura do tomateiro. In: GOTO R; TIVELLI SW (ed). Produção de hortaliças em ambiente protegido: condições subtropicais. São Paulo: UNESP. p. 257-319.

LOPES PRA. 1997. Influência da cobertura do solo e sistema de condução das plantas, na cultura do tomateiro (Lycopersicon esculentum Mill.) cultivado em casa de vegetação e no campo. Jaboticabal: UNESP-FCAV. $125 \mathrm{p}$. (Tese doutorado).

MARFÁ O; GURI S. 1999. Física de substratos y oxigenación del medio radicular. In: FERNÁNDEZ MF, GOMES IMC (ed). Cultivos sin suelo II. 2.ed. Almería: Dirección General de Investigatión y Formación Agraria; FIAPA; Caja Rural de Almería. p.93-106.
MAROUELLI WA; SILVA WLC; SILVA HR. 1996. Manejo da irrigação em hortaliças. 5. ed. Brasília: EMBRAPA. 72p.

MAROUELLI WA; CARRIJO OA; ZOLNIER S 2002a. Distribuição do sistema radicular do tomateiro, em fase de produção, em substratos acondicionados em contentores tipo bisnaga. Horticultura Brasileira 20: supl.2 CD-Room.

MAROUELLI WA; ZOLNIER S; CARRIJO AO. 2002b. Variabilidade espacial e temporal da tensão de água em substratos, acondicionados em contentores tipo bisnaga, com plantas de tomateiro. Horticultura Brasileira 20: supl. 2 CD-Room.

MARTINEZ HEP; BARBOSA JG. 1999. Substratos para hidroponia. Informe Agropecuário 20: 81-89.

MARTINS SR; FERNANDES HS; ASSIS FN; MENDEZ MEG. 1999. Caracterização climática e manejo de ambientes protegidos: a experiência brasileira. Informe Agropecuário 20: 15-23.

MORAES CAG; FURLANI PR. 1999. Cultivo de hortaliças de frutos em hidroponia em ambiente protegido. Informe Agropecuário 20: 106-113.

NORRIE J; GRAHAM MED; GOSSELIN A 1994. Potential evapotranspiration as a means of predicting irrigation timing in greenhouse tomatoes grown in peat bags. Journal of American Society of Horticultural Science 119: 163-168.

PÁDUA JG; GUSMÃO SAL de; GUSMÃO MTA de; BRAZ LT. 2002a. Densidade de plantio e produção de duas cultivares de tomateiro tipo "cereja", cultivadas em substrato, sob condições protegidas. Horticultura Brasileira 20: supl.2 CD-Room.

PÁDUA JG; GUSMÃO SAL de; GUSMÃO MTA de; BRAZ LT. 2002b Efeito da densidade de plantio e da cobertura de solo na produção de duas cultivares de tomateiro tipo "cereja". Horticultura Brasileira 20: supl.2 CD-Room.

RÖBER R. 2000. Substratos hortícolas: possibilidades e limites de sua composição e uso; exemplos da pesquisa, da indústria e do consumo. In: KÄMPF AN; FERMINO MH (eds). Substrato para plantas- a base da produção vegetal em recipientes. Porto Alegre: Genesis. p. 123-138.

VOLPE CA et al. 1989. Análise da precipitação mensal em Jaboticabal-SP. Ciência Agronômica 4: 3-5. 